\title{
Hyperinsulinemia restrains endometrial angiogenesis during decidualization in early pregnancy
}

\author{
Wenqi Chen 1,2,*, Siyu Lu1,2,*, Chengshun Yang1,2, Na Li1,2, Xuemei Chen 1,2, Junlin He1,2, Xueqing Liu1,2, Yubin Ding1,2, \\ Chao Tong3, Chuan Peng4, Chen Zhang1,2,3, Yan Su1,2, Yingxiong Wang ${ }^{1,2}$ and Rufei Gao1,2 \\ 'Laboratory of Reproductive Biology, School of Public Health and Management, Chongqing Medical University, Chongqing, China \\ 2Joint International Research Laboratory of Reproduction \& Development, Chongqing Medical University, Chongqing, China \\ ${ }^{3}$ Department of Obstetrics, The First Affiliated Hospital of Chongqing Medical University, Chongqing, China \\ ${ }^{4}$ Laboratory of Maternal and Fetal Medicine, The First Affiliated Hospital of Chongqing Medical University, Chongqing, China
}

Correspondence should be addressed to R Gao: gao_ru_fei@cqmu.edu.cn

*(W Chen and S Lu contributed equally to this work)

\begin{abstract}
Previous research on the role of insulin has focused on metabolism. This study investigated the effect of insulin on angiogenesis in endometrial decidualization. High insulin-treated mouse model was constructed by subcutaneous injection of insulin. Venous blood glucose, serum insulin, P4, E2, FSH and LH levels in the pregnant mice were detected by ELISA. Decidual markers, angiogenesis factors and decidual vascular network were detected during decidualization in the pregnant mouse model and an artificially induced decidualization mouse model. Tube formation ability and angiogenesis factors expression were also detected in high insulin-treated HUVECS cells. To confirm whether autophagy participates in hyperinsulinemia-impaired decidual angiogenesis, autophagy was detected in vivo and in vitro. During decidualization, in the condition of high insulin, serum insulin and blood glucose were significantly higher, while ovarian steroid hormones were also disordered $(P<0.05)$, decidual markers BMP2 and PRL were significantly lower $(P<0.05)$. Uterine CD34 staining showed that the size of the vascular sinus was significantly smaller than that in control. Endometrial VEGFA was significantly decreased after treatment with high insulin in vivo and in vitro $(P<0.05)$, whereas ANG-1 and TIE2 expression was significantly increased $(P<0.05)$. In addition, aberrant expression of autophagy markers revealed that autophagy participates in endometrial angiogenesis during decidualization $(P<0.05)$. After treatment with the autophagy inhibitor 3-MA in HUVEC, the originally damaged cell tube formation ability and VEGFA expression were repaired. This study suggests that endometrial angiogenesis during decidualization was impaired by hyperinsulinemia in early pregnant mice.
\end{abstract}
Key Words
- decidualization
- hyperinsulinemia
- angiogenesis
- embryo implantation
- autophagy 


\section{Introduction}

Insulin is a hormone that is secreted by pancreatic $\beta$-cells. Insulin promotes the uptake and utilization of glucose by binding to specific receptors on the target cell membrane and can inhibit glycogenolysis and gluconeogenesis of glycogen in the same way. In the past, research on the effect of insulin was mainly focused on metabolism. Recently, clinical studies have found a decrease in embryo implantation ability and a high rate of abortion after embryo implantation among patients with hyperinsulinemia (Dale et al. 1998, Chekir et al. 2005, Bellver et al. 2010). Abnormal endometrial thickness was also found in patients with polycystic ovary syndrome, often accompanied with hyperinsulinemia (Chekir et al. 2005, Iatrakis et al. 2006, Schulte et al. 2015). Studies have also shown that high levels of insulin could directly lead to abnormal embryo development (Marin-Juez et al. 2014, Laskowski et al. 2018). However, little has been reported on the regulatory effects of high-level insulin on the endometrium. Our previous study found that high levels of insulin could result in impaired endometrial receptivity and further affect endometrial decidualization in early pregnant mice (Li et al. 2017).

Angiogenesis, which is a vital part of endometrium decidualization, establishes a complex network of sinusoids and vasculature. The vascular network, which serves as a hub for the exchange of substances between the mother and the embryo, is critical for the maintenance of normal pregnancy (Kim et al. 2013, Winterhager et al. 2013). Studies have shown that insulin plays an important role in angiogenesis in many tissues and organs (Krishnapati \& Ghaskadbi 2016, Zeng et al. 2016). The occurrence of cerebral microvascular disease and lacunar infarction is related to hyperinsulinemia (Zunker et al. 1996). Here, we speculated that high levels of insulin may affect angiogenesis during endometrial decidualization.

Autophagy is the physiological cellular process through which intracellular components undergo lysosomemediated self-digestion and recycling. Under stress conditions such as auxotrophy, hypoxia, radiotherapy and chemotherapy, cells can regulate autophagy in a variety of ways to maintain normal metabolism and ensure cell survival (Senft \& Ronai 2015, Fritzen et al. 2016, Madrigal-Matute \& Cuervo 2016). Studies have shown that autophagy participates in a variety of physiological and pathological processes. Autophagy has been confirmed to be involved in embryonic angiogenesis using a chicken embryo model (Lu et al. 2016). Lu et al. demonstrated that Atg7, Atg8 and Beclin1 were expressed in the plexus vessels of angiogenesis at chick yolk sac membrane and chorioallantoic membrane. Interfering in autophagy with autophagy inducer or inhibitor could restrict the angiogenesis in vivo, which might be driven by the disorder of angiogenesis-related gene expressions and also lead to embryonic hemorrhage.

In this study, we first explored the effects of high insulin on endometrial angiogenesis during decidualization in early pregnant mice. Furthermore, whether autophagy is essential for impaired angiogenesis by high maternal insulin was also studied.

\section{Materials and methods}

\section{Animals}

Kunming mice (6-8 weeks old, weighing 25-30g) were provided by the Laboratory Animal Center of Chongqing Medical University (Certificate No: SCXK (YU) 20120001) and caged in a specific pathogen-free animal room under $12 \mathrm{~h}$ light $/ 12 \mathrm{~h}$ darkness. All animal procedures were approved by the Ethics Committee of Chongqing Medical University, China.

High insulin levels in pregnant mice were established as described by Zhang et al. (2017). Mice were randomly divided into two groups: high insulin group was given a subcutaneous injection of 0.05 IU insulin (Glargine, Sanofi, First Affiliated Hospital of Chongqing Medical University) at $09: 00 \mathrm{~h}$ and daily for 16 consecutive days, gradually increasing the dose to $0.8 \mathrm{IU}$ from 17 days to 22 days, and then maintaining at a dose of $0.2 \mathrm{IU}$ of insulin until the mice were killed (Fig. 1A). Control group was injected with $0.9 \%$ normal saline at the same time. Female mice were mated with normal males or vasectomized males to cause pregnancy or pseudopregnancy. The appearance of the vaginal plug was considered to be the first day of pregnancy (D1) or pseudopregnancy (PD1). Uterine endometrial tissues on D6, D7 and D8 were collected for further analyses. To construct the artificially induced decidualization model, $20 \mu \mathrm{L}$ of sesame oil (Sigma) was injected into one side of the uterus on the morning of PD4, whereas the other side of the uterus was left untreated. The uterus was collected on PD8. Parts of the uterine horns were fixed in formalin and embedded in paraffin, and the rest of the uterine tissues were stored at $-80^{\circ} \mathrm{C}$ for further analyses.

\section{Immunohistochemistry}

The uterus was extracted and fixed in 4\% paraformaldehyde solution and embedded in paraffin, and $4 \mu \mathrm{m}$ 
A

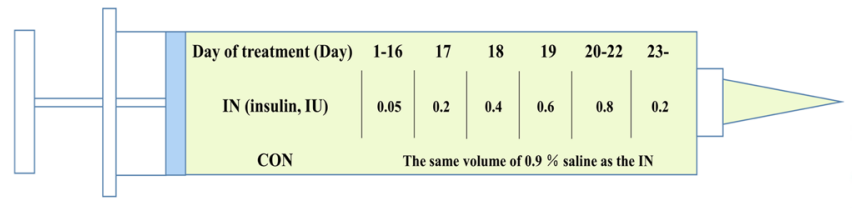

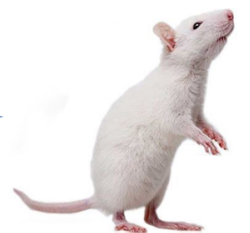

B
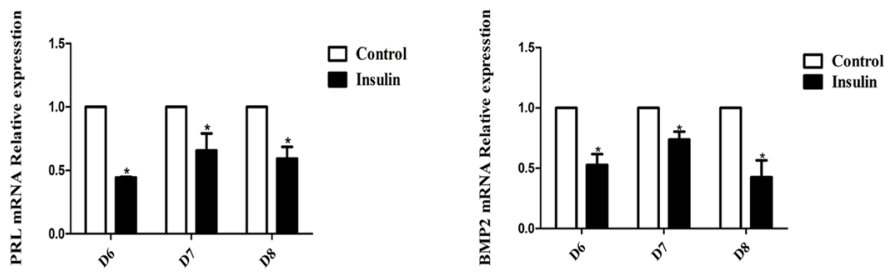

C $\frac{\text { D6 }}{\text { CON IN }}$

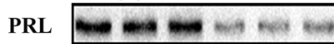
BMP2 $-2-1$ $\beta$-Actin $-\infty=$

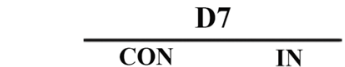
PRL BMP2 $--\infty-\cdots$ B-Actin $\infty-\infty$

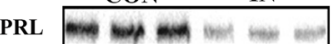

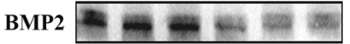
$\beta$-Actin $=-\infty-\infty$
D

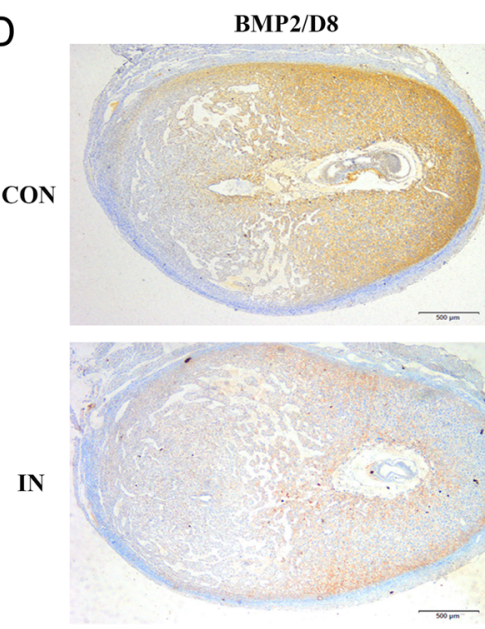

E

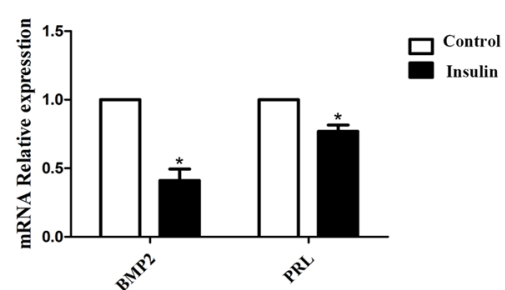

F

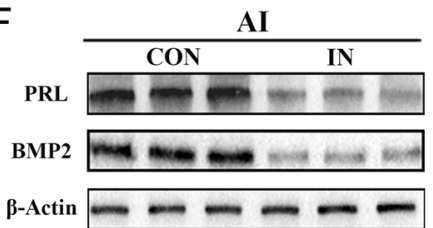

Figure 1

Endometrial decidualization was impaired by high maternal insulin levels. The daily intervention dose in each group is showed (A). The expression of BMP2 and PRL in the endometrium of pregnant mice on D6, D7 and D8 was analyzed by real-time PCR (B) and Western blot (C). The expression of BMP2 in the endometrium of pregnant mice on D8 was analyzed by immunohistochemistry (D). The expression of BMP2 and PRL in the endometrium of mice with artificially induced decidualization induced by oil injection was analyzed by real-time PCR (E) and Western blot (F). $n=3 . * P<0.05$. Al, artificially induced decidualization model by oil injection; $\mathrm{CON}$, control group; IN, high insulin group. sections were cut. Antigen retrieval was performed in EDTA antigen retrieval solution (Beyotime) for $20 \mathrm{~min}$ at $95^{\circ} \mathrm{C}$ followed by cooling naturally to room temperature for $1 \mathrm{~h}$. Endogenous peroxidase activity was inhibited by incubation with $3 \% \mathrm{H}_{2} \mathrm{O}_{2}$ for $10 \mathrm{~min}$. Nonspecific binding in tissue sections was blocked in $10 \%$ normal goat serum for $30 \mathrm{~min}$. The sections were incubated for $12 \mathrm{~h}$ at $4^{\circ} \mathrm{C}$ with primary antibody (Supplementary Table 1, see section on supplementary data given at the end of this article) followed by incubation with the corresponding biotinylated secondary antibodies. As a negative control, the primary antibody was replaced with normal rabbit IgG. The chromogenic reaction was conducted with diaminobenzidine (Zhongshan Biosciences, Beijing, China) for $3-5 \mathrm{~min}$ and terminated by rinsing the tissue with water. The sections were subsequently stained with hematoxylin. Finally, the image was taken using a microscope. For CD34 staining, the size of vascular sinus was quantified by ImageJ software.

\section{Western blotting}

Protein was extracted from 40 to $50 \mathrm{mg}$ decidual tissues using a cell lysis buffer for Western blotting and immunoprecipitation (Beyotime). Protein concentration was determined using the BCA Protein Assay kit (Beyotime). Tissues were boiled in $5 \times$ SDS sample loading buffer for $10 \mathrm{~min}$ and then loaded onto a 10\% SDSpolyacrylamide gel (Beyotime). Following electrophoresis, proteins were transferred onto PVDF membranes (Bio-Rad). 
The membranes were blocked for $80 \mathrm{~min}$ at room temperature in Tris-buffered saline with Tween (TBST) buffer containing 5\% nonfat milk. Immunoblotting was performed by incubating the membranes in $5 \%$ milk-TBST for $12 \mathrm{~h}$ at $4^{\circ} \mathrm{C}$ with primary antibody (Supplementary Table 1). Membranes were washed three times with TBST followed by incubation for $80 \mathrm{~min}$ with the secondary antibody at room temperature. After the membranes were washed three times with TBST, positive bands were detected by enhanced chemiluminescence reagents (Beyotime) and quantified by densitometry using Quantity One, version 4.4 .0 software. $\beta$-actin was used as a loading control for Western blotting.

\section{Real-time polymerase chain reaction (RT-PCR)}

Total RNA was extracted from the mouse endometrial tissues using TRIzol reagent (Invitrogen). RNA purity was assessed by measuring OD at 260 and $280 \mathrm{~nm}$ and A260/A280 $\geq 1.8$ was the standard. Its integrity was assessed by agarose gel electrophoresis. cDNA synthesis was completed with $1 \mu \mathrm{g}$ total RNA treated with DNase I in a $20 \mu \mathrm{L}$ reaction system using the First Strand Synthesis for RT-PCR kit (TaKaRa). cDNA was stored at $-20^{\circ} \mathrm{C}$ until real-time RT-PCR analysis. Specific primers for VEGFA, VEGFR2, ANG-1, TIE2, BMP2, PRL and $\beta$-actin were designed and produced by Sangon Biotech (Shanghai, China). The sequences of the primers used are shown in Table 1 . To compare transcript levels between the normal group and the high insulin group, real-time RT-PCR was performed with SYBR Premix Ex Taq kits (Takara) and the Bio-Rad CFX96 Real-Time System (Bio-Rad). The realtime RT-PCR master mixture $(15 \mu \mathrm{L})$ consisted of $7.5 \mu \mathrm{L}$ of $2 \times$ SYBR Premix Ex Taq, $0.6 \mu \mathrm{L}$ of $10 \mathrm{pmol} / \mathrm{mL}$ primers, $1.2 \mu \mathrm{L}$ of cDNA and $5.1 \mu \mathrm{L}$ of double-distilled $\mathrm{H}_{2} \mathrm{O}$. The PCR conditions were as follows: initial denaturation at $98^{\circ} \mathrm{C}$ for $30 \mathrm{~s}, 40$ cycles of $10 \mathrm{~s}$ at $98^{\circ} \mathrm{C}$, and $30 \mathrm{~s}$ at the corresponding primer melting temperature (Tm). Experiments were performed in triplicate for each sample. RNA template was replaced with nuclease-free water for negative control. Melting curves of the products were obtained after cycling using a stepwise increase in temperature from $55^{\circ} \mathrm{C}$ to $95^{\circ} \mathrm{C}$. Relative gene expression levels were calculated with the $2^{-\Delta \Delta C t}$ method, with $\beta$-actin as the internal control.

\section{Human umbilical vein endothelial cells (HUVECS)}

HUVECS were provided by Dr Chao Tong (Chongqing Medical University, Chongqing, China). HUVECS were cultured in medium 1640 (Gibco, Thermo Fisher Scientific) containing 10\% fetal bovine serum (Gibco) and $0.1 \%$ antibiotics (Beyotime). Cultures were maintained at $37^{\circ} \mathrm{C}$ in a humidified $95 \%$ air and $5 \% \mathrm{CO}_{2}$ atmosphere. There is insulin recombinant full chain in the culture medium and its concentrations are $10 \mathrm{mg} / \mathrm{L}$ (about $2 \mathrm{pmol} / \mathrm{L})$. In the cell culture, cells were supplemented with another $100 \mathrm{nmol} / \mathrm{L}$ insulin for high insulin treatment. HUVECS were divided into three groups: high insulin group: HUVECS supplemented with $100 \mathrm{nmol} / \mathrm{L}$ insulin (Sigma) for 24h ( $\mathrm{Li}$ et al. 2015a). 3-MA+high insulin group: 3-methyladenine (3-MA, $10 \mathrm{mM}$, Sigma) was added $30 \mathrm{~min}$ before HUVEC incubation with insulin (Chen et al. 2017), and the control group was cultured in parallel over $24 \mathrm{~h}$ without 3-MA or insulin (Chen et al. 2017). The actions of 3-MA, an autophagy inhibitor, was identified by examining the expression of autophagy markers.

\section{Immunofluorescence}

HUVECS were cultured on slides. After the slides were washed with PBS, the sections were fixed in cold methanol for $30 \mathrm{~min}$ at $4^{\circ} \mathrm{C}$ and blocked with $2 \%$ BSA for $1 \mathrm{~h}$ at $37^{\circ} \mathrm{C}$. Primary antibodies against LC3 and VEGFA were applied on cells overnight at $4^{\circ} \mathrm{C}$. Then, the cells were incubated with fluorescein isothiocyanate-labeled rabbit IgG for $1 \mathrm{~h}$ at $37^{\circ} \mathrm{C}$ in the dark after incubation with DAPI (Beyotime) and sealed with glycerine (50\%). Image acquisition was performed using a fluorescence microscope.

Table 1 Sequences of forward and reverse primers used in real-time RT-PCR.

\begin{tabular}{|c|c|}
\hline Gene & Forward $\left(5^{\prime} \rightarrow 3^{\prime}\right)$ \\
\hline VEGFA & GTCCAACTTCTGGGCTCTTCT \\
\hline VEGFR2 & TGGCAAATACAACCCTTCAGA \\
\hline BMP2 & ACGTCCTCAGCGAATTTGAG \\
\hline PRL & GAGAGCTGTTTGACCGTGTG \\
\hline ANG-1 & CCAGGCCCGTTGTTCTTGAT \\
\hline TIE2 & GAGTCAGCTTGCTCCTTTATGG \\
\hline$\beta$-Actin & CCTGAGGCTCTTTTCCAGCCT \\
\hline
\end{tabular}

Reverse $\left(5^{\prime} \rightarrow 3^{\prime}\right)$

СССТСТССТСТTССТТСТСТTC

TGTCACCAATACCCTTTCCTCAG

TTTCCCACTCATCTCTGGAAGT

TGTAGCCAGGGAAGAAGTGG

GGAAGGGAGACTTGCTCATTC

AGACACAAGAGGTAGGGAATTGA

AGAGGTCTTTACGGATGTCAACG 


\section{Tube formation}

Equal amounts of HUVEC suspension at a concentration of $4-5 \times 10^{5}$ cells $/ \mathrm{mL}$ were added to each well of a 96-well culture plate that was precoated with $50 \mu \mathrm{L}$ of growth factor-reduced Matrigel. The cells were treated for $6 \mathrm{~h}$ at $37^{\circ} \mathrm{C}$. Tube formation was observed under an inverted microscope (Eclipse TS100, Nikon), and images were captured with the use of a CCD color camera (KP-D20AU: Hitachi, Ibaraki, Japan) and Apple iMovie 7.1.4 software.

\section{Detection of serum insulin, P4, E2, FSH, LH and blood glucose}

Blood samples were collected from the eye socket and placed at room temperature for 3-4h to obtain the serum. The serum levels of insulin, P4, E2, FSH and LH were detected by enzyme-linked immunosorbent assay (ELISA, Yan Hui Biological Technology, Shanghai, China) with the intra-assay CV and inter-assay CV of $15 \%$.

\section{Statistical analysis}

Data were analyzed using the SPSS 16.0. Data are given as the mean \pm s.D. The differences between two groups were analyzed by Student's $t$-test. The differences among more than two groups were analyzed with one-way ANOVA. The differences were considered significant if $P<0.05$. All the experiments were repeated at least three times.

\section{Results}

\section{High insulin pregnant mice showed disordered reproductive hormone levels}

Serum insulin and venous blood glucose were measured to verify the validity of the high insulin pregnant mouse model $(n=6)$. As shown in Table 2 , both the serum insulin and venous blood glucose levels were significantly increased in the high insulin pregnant mice $(P<0.05)$. Steroid hormones are essential for a successful pregnancy. Angiogenesis during decidualization could be impaired under conditions of abnormal steroid hormone levels (Chandana et al. 2010). A trend for a relative reduction in serum E2, P4, FSH and LH levels in the high insulin pregnant mice compared to those in the control mice was found on D6-D8 (Table 2). This finding suggested that high maternal insulin levels may result in disordered reproductive hormones during decidualization.

\section{Endometrial angiogenesis during decidualization was impaired under high maternal insulin levels}

BMP2 and PRL are important for decidualization in early pregnancy (Eyal et al. 2007, Li et al. 2007). The expression of endometrial PRL and BMP2 on D6, D7 and D8 was significantly lower in early pregnant mice given high insulin treatment than in control mice (Fig. 1B, C and D). An in vivo artificially induced decidualization model that was induced by injecting oil into the horn of the uterus was also used to show the roles of high maternal insulin levels on decidualization. According to the results,

Table 2 Venous blood glucose, serum insulin, E2, P4, LH and FSH levels in the pregnant mice.

\begin{tabular}{|c|c|c|c|c|}
\hline & & Control & Insulin & $\boldsymbol{P}$ \\
\hline \multirow[t]{6}{*}{ D6 } & Insulin (mIU/L) & $17.52 \pm 0.61709$ & $29.35 \pm 1.065$ & $<0.0001$ \\
\hline & Blood glucose (pg/mL) & $8.429 \pm 0.1848$ & $9.829 \pm 0.2427$ & $<0.05$ \\
\hline & E2 (pg/mL) & $45.60 \pm 1.732$ & $55.34 \pm 2.139$ & $>0.05$ \\
\hline & P4 (ng/mL) & $8.383 \pm 0.1858$ & $7.625 \pm 0.2114$ & $<0.05$ \\
\hline & $\mathrm{LH}(\mathrm{mlU} / \mathrm{mL})$ & $4.206 \pm 0.1079$ & $3.750 \pm 0.1249$ & $<0.05$ \\
\hline & $\mathrm{FSH}(\mathrm{mlU} / \mathrm{mL})$ & $62.67 \pm 2.85$ & $48.47 \pm 1.550$ & $<0.05$ \\
\hline \multirow[t]{6}{*}{ D7 } & Insulin (mIU/L) & $17.64 \pm 0.6738$ & $31.96 \pm 0.8897$ & $<0.0001$ \\
\hline & Blood glucose (pg/mL) & $8.329 \pm 0.3115$ & $10.06 \pm 0.3457$ & $<0.05$ \\
\hline & E2 (pg/mL) & $57.69 \pm 1.848$ & $52.19 \pm 1.985$ & $>0.05$ \\
\hline & P4 (ng/mL) & $7.031 \pm 0.1822$ & $6.730 \pm 0.2202$ & $>0.05$ \\
\hline & $\mathrm{LH}(\mathrm{mlU} / \mathrm{mL})$ & $3.420 \pm 0.1064$ & $3.251 \pm 0.1284$ & $>0.05$ \\
\hline & $\mathrm{FSH}(\mathrm{mlU} / \mathrm{mL})$ & $56.97 \pm 1.369$ & $42.26 \pm 1.515$ & $<0.05$ \\
\hline \multirow[t]{6}{*}{ D8 } & Insulin (mIU/L) & $18.11 \pm 0.5295$ & $33.12 \pm 0.9122$ & $<0.0001$ \\
\hline & Blood glucose (pg/mL) & $8.567 \pm 0.2929$ & $10.43 \pm 0.4169$ & $<0.05$ \\
\hline & E2 (pg/mL) & $63.12 \pm 1.029$ & $55.34 \pm 2.139$ & $<0.05$ \\
\hline & P4 (ng/mL) & $6.730 \pm 0.2202$ & $5.800 \pm 0.1929$ & $<0.05$ \\
\hline & $\mathrm{LH}(\mathrm{mlU} / \mathrm{mL})$ & $3.018 \pm 0.06714$ & $2.701 \pm 0.1119$ & $<0.05$ \\
\hline & $\mathrm{FSH}(\mathrm{mlU} / \mathrm{mL})$ & $51.82 \pm 0.8410$ & $35.83 \pm 1.407$ & $<0.05$ \\
\hline
\end{tabular}

E2, estrogen; FSH, follicle-stimulating hormone; LH, luteinizing hormone; P4, progesterone $(n=6)$.

$\begin{array}{lr}\text { https://joe.bioscientifica.com } & \text { (c) } 2019 \text { Society for Endocrinology } \\ \text { https://doi.org/10.1530/JOE-19-0127 } & \text { Published by Bioscientifica Ltd. } \\ \text { Printed in Great Britain }\end{array}$
Printed in Great Britain 
the levels of both BMP2 and PRL on the oil-injected side uterus were also significantly decreased by high insulin treatment (Fig. 1E and F).

Angiogenesis, which establishes a network of vessels and sinusoids to support embryo development, is essential for endometrial decidualization. To determine whether there was any serious loss of endometrial angiogenesis under high maternal insulin levels during decidualization, the structure of blood vessels and vascular remodeling were analyzed. The results showed that there was no significant difference in vascular density, but the enlargement and elongation of the vascular sinus folding area were altered; the large-sized vascular sinus folding in the central region was markedly smaller in the high insulin group than in the control group, as evidenced by CD34 staining (Fig. 2A). The size of the vascular sinus folding on the decidual uterus induced by oil injection was also significantly smaller in the high insulin group (Fig. 2D). The same results were obtained in vitro. Tube formation of HUVECS was compromised by high insulin levels (Fig. 3A). VEGFA, VEGFR2, ANG-1 and TIE2 are key molecules that regulate decidual angiogenesis and maternal spiral artery remodeling. The results showed that endometrial ANG-1 and TIE2 mRNA were significantly increased, while VEGFA and VEGFR2 mRNA expression was significantly decreased on D6 to D8 in the high insulin group compared to those in the control group (Supplementary Fig. 1A, B, C and D). The protein expression of these markers detected by Western blot and immunohistochemistry was consistent with the mRNA expression (Fig. 2B, E and F). After artificially induced decidualization by oil injection in vivo, the expression of
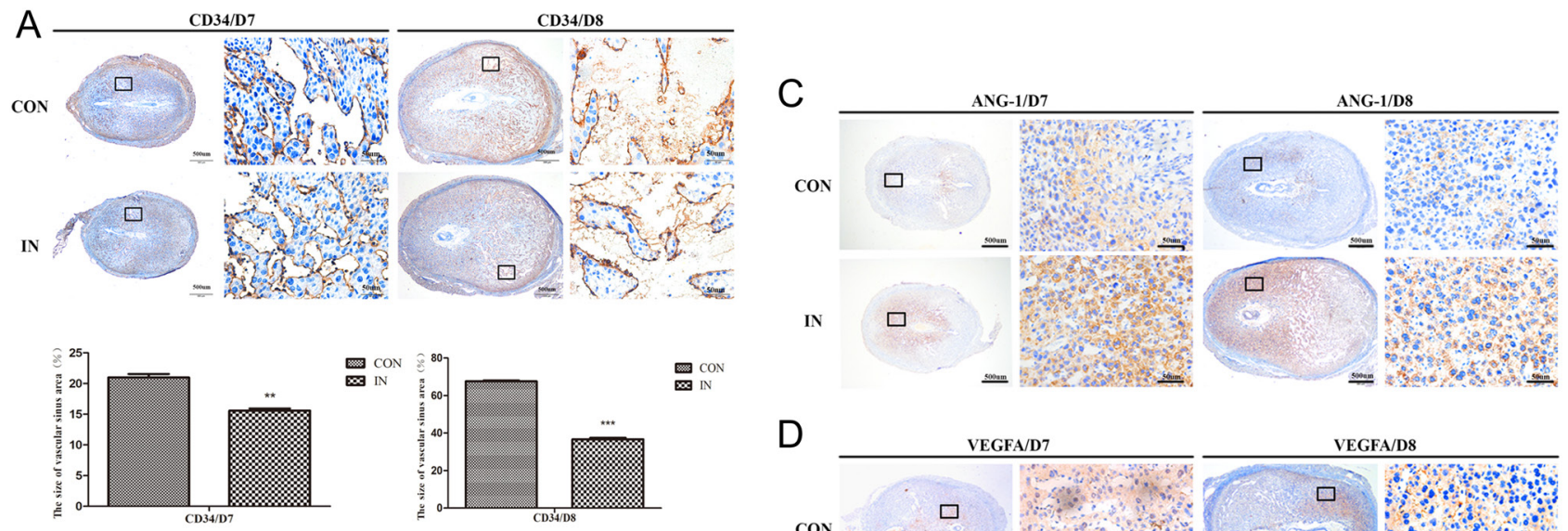

$\underset{\mathrm{N}}{\mathrm{CON}}$

D
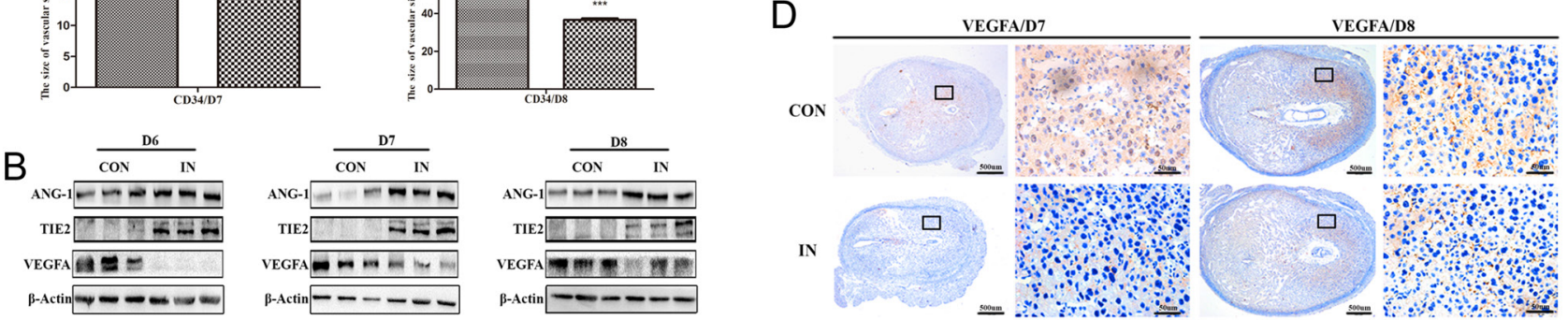

$\mathrm{E}$
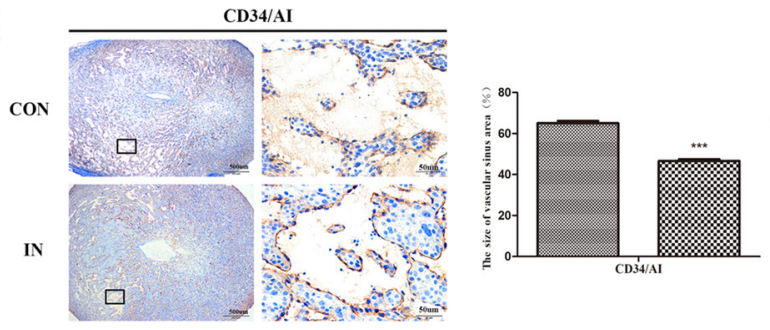

$\stackrel{\mathrm{B}}{\mathrm{CON}}$

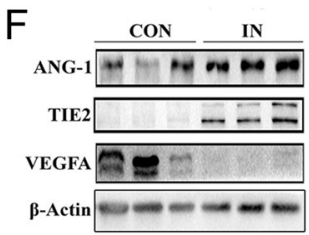

Figure 2

Angiogenesis in endometrium decidualization was restrained by high maternal insulin levels in vivo. The endometrial expression of CD34 in pregnant mice on D7 and D8 (A) was analyzed by immunohistochemistry. The histogram showed the size of vascular sinus area on day 7 of pregnancy. The expression of ANG-1, TIE2, and VEGFA in the endometrium of pregnant mice on D6, D7 and D8 was analyzed by Western blot (B). Immunohistochemistry analysis of the expression of ANG-1 (C) and VEGFA (D) in the endometrium of pregnant mice on D7 and D8. The endometrial expression of CD34 in decidual endometrium artificially induced by oil injection in vivo (E) was analyzed by immunohistochemistry. The histogram showed the size of vascular sinus area in decidual endometrium. The expression of ANG-1, TIE2 and VEGFA in artificially induced decidual endometrium was analyzed by Western blot (F). $n=3$. Al, artificially induced decidualization model by oil-injected; CON, control group; IN, high insulin group. 


\begin{tabular}{l|l|l|r|r|}
$\begin{array}{l}\text { Journal of } \\
\text { Endocrinology }\end{array}$ & W Chen, S Lu et al. & $\begin{array}{l}\text { Hyperinsulinemia and decidual } \\
\text { angiogenesis }\end{array}$ & $\mathbf{2 4 3 : 2}$ & $\mathbf{1 4 3}$ \\
\hline
\end{tabular}

A

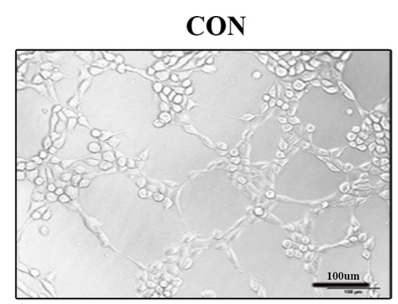

B

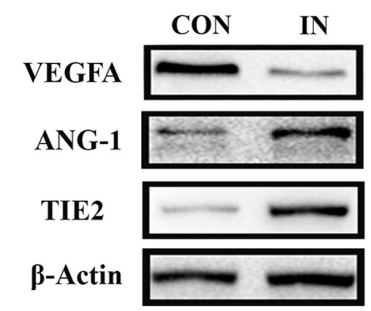

D
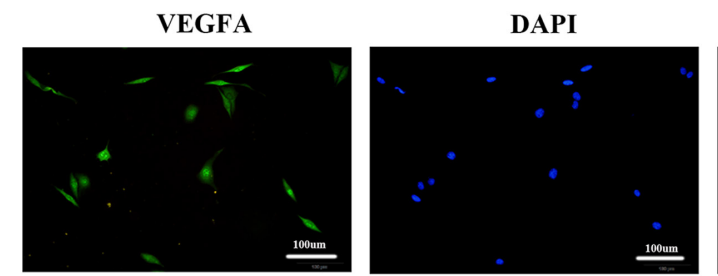

IN

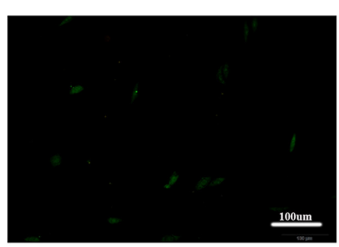

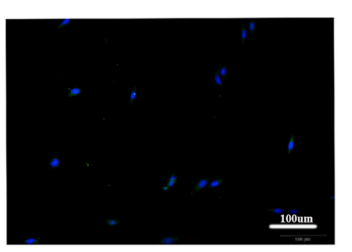

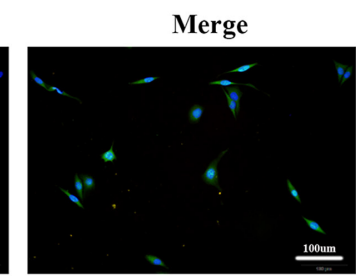

IN

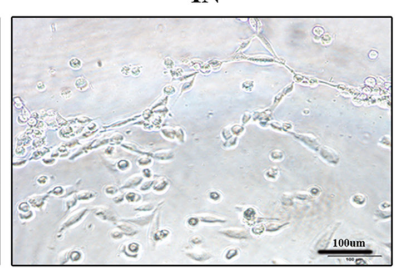

C
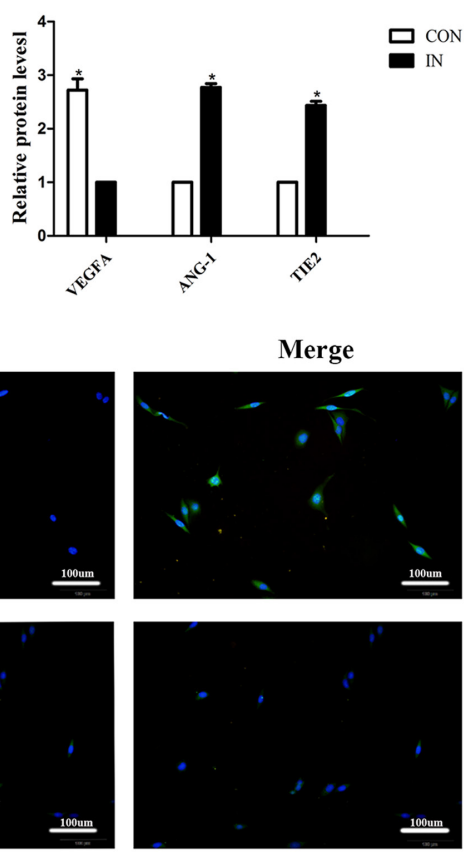

Figure 3

Angiogenesis was compromised by high insulin levels in vitro. Tube formation of HUVECS was compromised under the role of high insulin levels (A). The expression of ANG-1, TIE2 and VEGFA in HUVECS was detected by Western blot (B). The histogram shows the quantification of the Western blot results. (C). Immunofluorescence staining results showed the different expression of VEGFA in HUVECS between the high insulin group and the control group (D). $n=3 .{ }^{*} p<0.05$. CON, control group; IN, high insulin group.
VEGFA and VEGFR2 was significantly decreased, but the expression of ANG-1 and TIE2 was markedly increased in the high insulin group compared to those in the control group (Fig. 2C, D and Supplementary Fig. 1E). After treatment with high levels of insulin in HUVECS, the protein expression of VEGFA was significantly decreased, while ANG-1 and TIE2 protein expression was obviously increased (Fig. 3B, C and D). These results suggested that angiogenesis in endometrium decidualization was restrained by high maternal insulin levels.

\section{Autophagy, which was mediated by high insulin levels, was responsible for the inhibition of endometrial angiogenesis during decidualization}

Autophagy plays an important role in various cellular processes and contributes to many physiological and pathological processes. Autophagy-related markers LC3B, P62, Atg5 and Beclin1 in the endometrium on D6, D7 and D8 were analyzed by Western blotting. During the process of autophagy, LC3B changes dynamically, and an increase in LC3B-II is representative of the accumulation of autophagosomes. High maternal insulin levels enhanced the conversion of LC3B-I into LC3B-II in the decidual endometrium, and the expression of Atg5 and Beclin1, markers of autophagic induction, was also increased (Fig. 4A). P62 is an autophagy-specific substrate, and the accumulation of this protein is considered a hallmark of impaired autophagic degradation. In the present study, decreased endometrial p62 was found in mice with high insulin levels (Fig. 4A). These results suggested that endometrial autophagy during decidualization was triggered by high insulin in vivo. As shown in Fig. 4B, the same results were obtained in high insulin-treated HUVECS in vitro. Strong LC3B staining in HUVECS was found after insulin treatment. In addition, the upregulation of autophagy markers induced by high insulin was restored by 3-MA, an inhibitor of autophagy (Fig. 5A and B). 3-MA treatment reversed both the restrained tube formation and impaired expression of the pro-angiogenic factor VEGFA under high insulin conditions (Fig. 5C and D). These data suggested that enhanced autophagy was responsible for the inhibited endometrial angiogenesis resulting from high insulin levels during decidualization. 
A
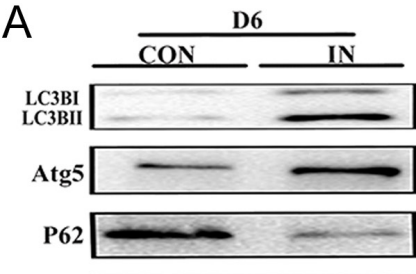

Beclin

$\beta$-Actin

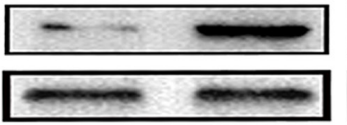

B
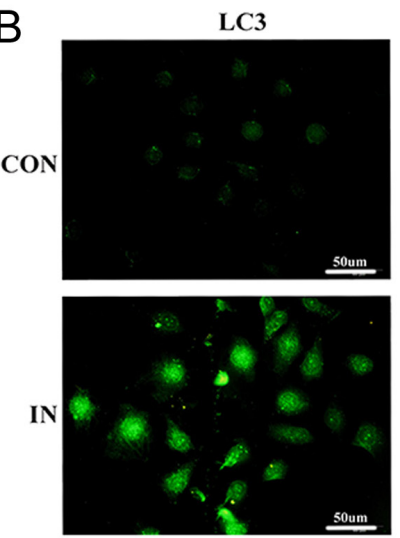

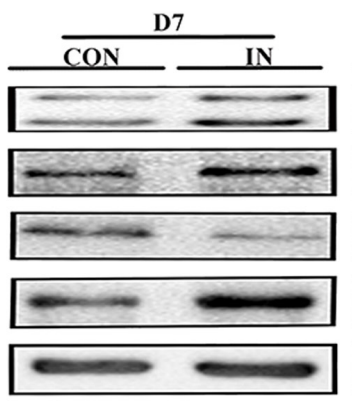

DAPI
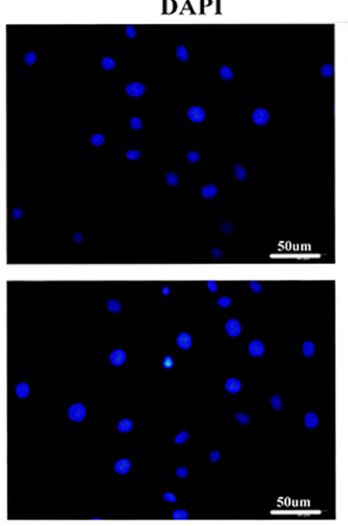
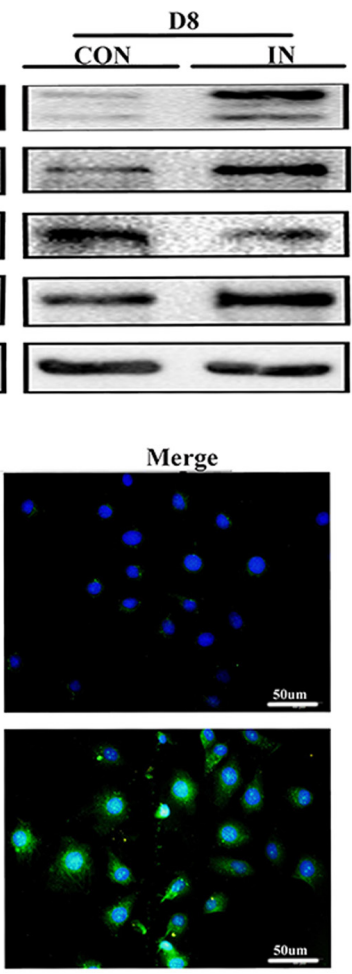

\section{Figure 4}

Autophagy was triggered by high insulin levels during decidualization. The expression of autophagy-related factors LC3B, P62, Atg5 and Beclin1 in the endometrium of pregnant mice on D6, D7 and D8 was analyzed by Western blot (A). Immunofluorescence staining results showed increased expression of LC3B in HUVECS in the high insulin group (B). $n=3$. CON, control group; $\mathrm{IN}$, high insulin group.
A

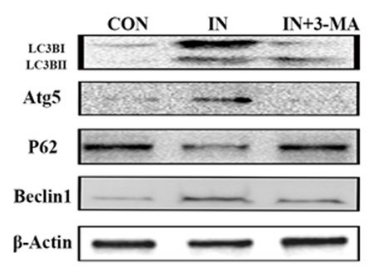

B

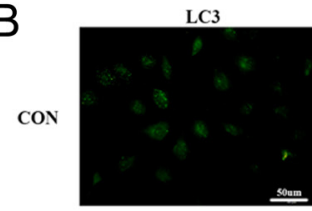

IN
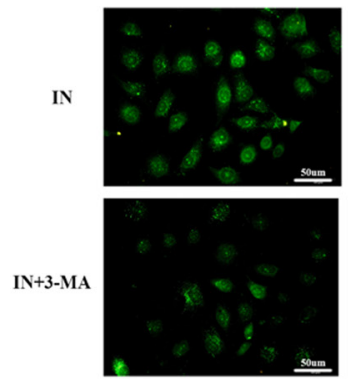

DAPI
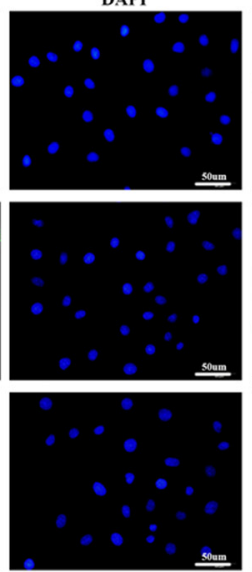

Merge
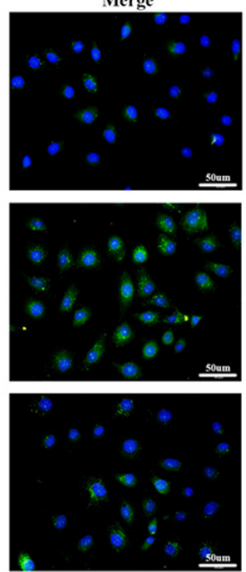

C

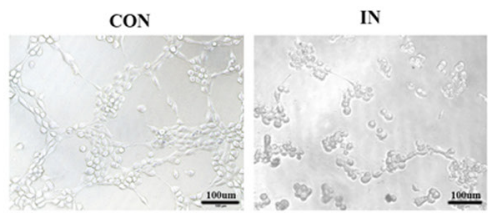

D
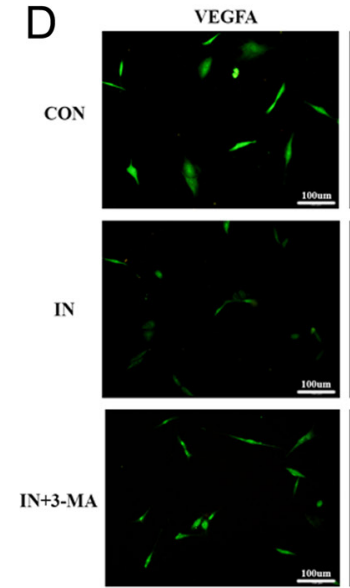
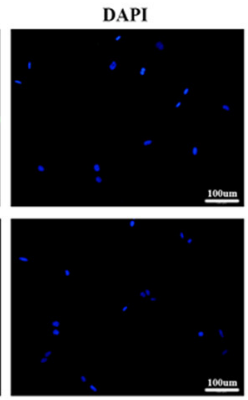

IN+3-MA

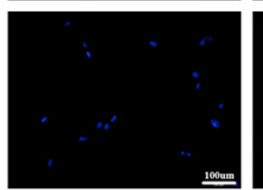

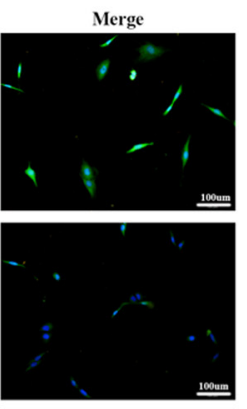

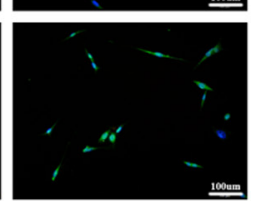

Figure 5

Enhanced autophagy was responsible for the inhibition of angiogenesis resulting from high insulin levels. The expression of LC3B, P62, Atg5 and Beclin1 in HUVECS was analyzed by Western blot (A). Immunofluorescence staining with LC3B in HUVECS was compared among the CON, IN and IN + 3-MA groups (B). Tube formation of HUVECS was compared among the CON, IN and IN + 3-MA groups (C). Immunofluorescence staining with VEGFA in HUVECS was compared among the CON, IN and IN + 3-MA groups (D). $n=3$. CON, control group; IN, high insulin group; IN + 3-MA, high insulin + 3-MA group. 


\section{Discussion}

The role of insulin, a protein hormone produced by beta cells of the pancreatic islets, in the metabolic regulation of carbohydrates, fats and proteins by promoting the absorption of carbohydrates, especially glucose from the blood into liver, fat and skeletal muscle cells, has been well studied. Recently, studies have explored abnormal oocyte, embryo development and lower embryo implantation rate in women with PCOS, obesity and type 2 diabetes (Chekir et al. 2005, Bellver et al. 2010). Hyperinsulinemia and insulin resistance are established characteristics of women with PCOS, obesity and type 2 diabetes. The associations between abnormal oocytes and embryos and hyperinsulinemia have been well explored. However, the role of hyperinsulinemia and insulin resistance in the maternal endometrium during pregnancy remains unknown. In mice, the uterus becomes receptive for embryos on day 4 of pregnancy (day 1, vaginal plug), and the attachment of the blastocyst to the uterine luminal epithelium occurs on day 4 of pregnancy between 22:00 and 24:00 h. With the initiation of attachment, endometrial stromal cells surrounding implanting blastocysts undergo decidual transformation (decidualization), which may last until day 8 of pregnancy. Our previous study found that high maternal insulin could result in impaired endometrial receptivity during embryo implantation. Here, we found that endometrial PRL and BMP2, well-known markers for decidualization, were significantly decreased on day $6-8$ of pregnancy following high insulin treatment. The implanting blastocyst stimulates the onset of decidualization in the uterus. This process could be initiated by experimental manipulation through intraluminal oil infusion in a receptive pseudopregnant uterus. Using this artificially induced decidualization model, we also found that both PRL and BMP2 were obviously declined in mice treated with high insulin. These data suggested that high insulin could impair decidualization in mice.

Angiogenesis in endometrium decidualization forms a vascular network that serves as the exchange apparatus between maternal circulation and the embryo, which is necessary for embryonic survival and a successful pregnancy (Li et al. 2015b). Studies have shown that insulin can positively and negatively regulate vascular endothelial cells. In animal experiments, physiological concentrations or low concentrations of insulin $(0.1-1.0 \mathrm{nmol} / \mathrm{L})$ promote the proliferation of endothelial progenitor cells (EPCs), while $10 \mathrm{nmol} / \mathrm{L}$ insulin does not promote the proliferation of EPCs (Muniyappa \& Quon 2007).
According to our finding, there was no decrease in endometrial vascular density, but the enlargement and elongation of the vascular sinus-folding area were altered and the large-sized vascular sinus folding in the central region was markedly smaller after high insulin treatment. Here we found that VEGFA/VEGFR2 was significantly decreased, while ANG-1/TIE2 was significantly increased on D6 to D8 in the high insulin group compared to those in the control group. As we know, VEGF is critical for angiogenesis, and its role in promoting new blood vessel growth has been extensively investigated (Hicklin \& Ellis 2005). It is reported that VEGFA plays a role in VEGF-induced vascular permeability and angiogenesis in the uterus required for implantation (Halder et al. 2000) and is very important in regulating angiogenesis in endometrium decidualization and maternal spiral artery remodeling (Okada et al. 2014). The endometrium decidualization are rich sources of angiogenic growth factors (Reynolds et al. 1992). Although VEGFA/VEGFR2 was significantly decreased, the other angiogenic growth factors may be compensatory increased and result in no significant difference in endometrial vascular density in the role of high insulin (Ferrara \& Kerbel 2005, Fallah et al. 2019). The ANG/TIE2 system is also a key regulator of angiogenesis. The expression of membrane-bound ( $\mathrm{mb})$ TIE2 and ANG-1 ensures vessel stability, whereas ANG-2 inducible in endothelial cells antagonizes the ANG-1/TIE2 pathway by competing with ANG-1. Although ANG-1/TIE2 was significantly increased in the high insulin group in our studies, it was not detected whether ANG-2/TIE2 was activated in the condition of high insulin. According to the results which showed that the large-sized vascular sinus folding in the central region was markedly smaller after high insulin treatment, we speculated that the role of ANG-2/TIE2 may be more effective than that of ANG-1/TIE2. Studies showed that Ang-2 has vessel-destabilizing effects and induces regression of microvessels in the absence of VEGF (Maisonpierre et al. 1997, Scharpfenecker et al. 2005). In these studies, the decreased VEGFA and smaller large-sized vascular sinus folding implied that ANG-2 may have participated in the impaired decidual angiogenesis in the role of high insulin. HUVEC is widely used for angiogenesis. However, it is far from ideal to represent decidual vasculature which is microvascular. Additional models should be used to confirm the role of high insulin levels on endometrial angiogenesis.

Here we found that high levels of insulin could result in impaired endometrial angiogenesis during decidualization in early pregnant mice. At the same 
time, hyperglycemia was also observed in the high insulin pregnant mice. Growing evidence supports the importance of glucose for endometrium. Dysregulated glucose transporter expression represents an understudied contributor to impaired decidualization (von Wolff et al. 2003, Frolova \& Moley 2011a,b). Nacar et al. found that diabetes could decrease leukocyte proportions in decidua in early pregnancy periods (Nacar et al. 2016). In streptozotocin-induced diabetic pseudopregnant rats, there is impaired endometrial decidualization compared to control (Zakaria et al. 2000). Wang et al. also found that the implantation rate is significantly reduced in diabetic mice compared to controls, and the change of uterine environment is the main reason leading to the decreased implantation rate (Wang et al. 2015). Venous blood glucose levels were significantly increased in the high insulin pregnant mice in this study. Here, it was difficult to define in vivo the possibility that the findings are due to increased glucose levels, rather than increased insulin levels. Although it could not be excluded that the increased glucose levels induced by hyperinsulinemia also play roles in the impaired endometrial angiogenesis, hyperinsulinemia is the primary intervention in our experiments. More studies should be done to explore the role of increased glucose levels after insulin treatment for the impaired endometrial angiogenesis.

Autophagy is a conserved recycling process induced by starvation or various external or internal cellular stresses and involves the degradation of cellular constituents in lysosomes to maintain energy levels (Senft \& Ronai 2015, Madrigal-Matute \& Cuervo 2016). Autophagy has an important role in various cellular processes and contributes to many normal and pathological processes (Fritzen et al. 2016). mTOR is an evolutionarily conserved serine/threonine protein kinase that plays a critical role in autophagy (Alers et al. 2012, Zhao et al. 2015). A central role of mTOR in controlling insulin processing by regulating cap-dependent translation of carboxypeptidase $\mathrm{E}$ in a 4EBP2/eIF4E-dependent manner has also been found in many studies (Blandino-Rosano et al. 2017). All these results suggest that insulin regulates autophagy. Studies have shown that skeletal muscle autophagy is suppressed by insulin and that autophagy remains responsive to the suppressive effects of insulin in otherwise insulin-resistant and obese mice (Ehrlicher et al. 2018). Insulin could decrease autophagy and lead to cartilage degradation (Ribeiro et al. 2016). Our group also found that following insulin treatment, an imbalance in autophagy appeared in the ovary during early pregnancy (Su et al. 2017). Here, enhanced autophagy, as evidenced by increased LC3B and
Atg5 and decreased P62, was found during decidualization under high maternal insulin levels in vivo. Additionally, compromised angiogenesis evidenced by tube formation after treatment with high insulin in vitro could be restored by the autophagy inhibitor 3-MA. Although these results appear to contradict those from previous studies, the different concentrations of insulin used may explain these opposing results. Insulin may play a negative role in autophagy at physiological concentrations, while it may play a positive role in autophagy at higher concentrations, even under conditions of insulin resistance. The different effects of insulin on autophagy at different levels is an interesting area of study.

The E2 and/or P4-mediated events are thought to be accomplished by the expression of a unique set of genes in the uterus. During decidualization, female sex steroid hormones directly regulate several genes, including vitellogenin, PRL, uteroglobin, ovalbumin, progesterone receptor, and lactoferrin, in target cells because of the presence of the steroid-responsive elements in their promoter sequences (Kumar et al. 1997, Niswender et al. 2000). Uterine stromal cells undergo a steroid hormonedependent transformation into morphologically and functionally distinct decidual cells in a unique process known as decidualization. Studies have shown that estrogen can directly modulate angiogenesis via effects on endothelial cells and can regulate the expression and secretion of angiogenic factors, such as VEGF, by glandular epithelial cells of the endometrium to regulate endometrial angiogenesis (Albrecht et al. 2003, Kim et al. 2013). In this study, high insulin mice presented a decreasing trend in serum levels of $\mathrm{P} 4$ and $\mathrm{E} 2$ relative to those in control mice on D6-8. This finding suggested that disordered ovarian steroid hormones may be related to abnormal angiogenesis during decidualization. Insulin receptor expression in endometrium was observed to be present primarily in the secretory phase and localized at the stromal cells, whereas its expression was downregulated from follicular to luteal phases (Mioni et al. 2012). Yang et al. found treatment of the HUVECs with high insulin impaired insulin signaling, with reductions in the tyrosine phosphorylation of IR and protein expression of IRS-1 by almost 65\%, respectively (Yang et al. 2016). Although disordered ovarian steroid hormones, especially P4 and E2, were detected in the animals treated with high doses of insulin that showed abnormal angiogenesis during decidualization, the role of the altered steroid concentrations in the abnormal angiogenesis was not determined. Exploring the relative contributions of altered steroid concentrations and direct insulin actions in this process would be warranted. 


\section{Supplementary data}

This is linked to the online version of the paper at https://doi.org/10.1530/ JOE-19-0127.

\section{Declaration of interest}

The authors declare that there is no conflict of interest that could be perceived as prejudicing the impartiality of the research reported.

\section{Funding}

This work was supported by the National Natural Science Foundation of China (No. 81300486, No. 31571190, No. 31771663), the Natural Science Foundation of Chongqing (No. cstc2015jcyjA10013, cstc2018jcyjAX0309).

\section{References}

Albrecht ED, Babischkin JS, Lidor Y, Anderson LD, Udoff LC \& Pepe GJ 2003 Effect of estrogen on angiogenesis in co-cultures of human endometrial cells and microvascular endothelial cells. Human Reproduction 18 2039-2047. (https://doi.org/10.1093/humrep/ deg415)

Alers S, Loffler AS, Wesselborg S \& Stork B 2012 Role of AMPK-mTORUlk1/2 in the regulation of autophagy: cross talk, shortcuts, and feedbacks. Molecular and Cellular Biology 32 2-11. (https://doi. org/10.1128/MCB.06159-11)

Bellver J, Ayllon Y, Ferrando M, Melo M, Goyri E, Pellicer A, Remohi J \& Meseguer M 2010 Female obesity impairs in vitro fertilization outcome without affecting embryo quality. Fertility and Sterility 93 447-454. (https://doi.org/10.1016/j.fertnstert.2008.12.032)

Blandino-Rosano M, Barbaresso R, Jimenez-Palomares M, Bozadjieva N, Werneck-De-Castro JP, Hatanaka M, Mirmira RG, Sonenberg N, Liu M, Ruegg MA, et al. 2017 Loss of mTORC1 signalling impairs beta-cell homeostasis and insulin processing. Nature Communications 816014. (https://doi.org/10.1038/ncomms16014)

Chandana EP, Maeda Y, Ueda A, Kiyonari H, Oshima N, Yamamoto M, Kondo S, Oh J, Takahashi R, Yoshida Y, et al. 2010 Involvement of the Reck tumor suppressor protein in maternal and embryonic vascular remodeling in mice. BMC Developmental Biology 10 84. (https://doi. org/10.1186/1471-213X-10-84)

Chekir C, Nakatsuka M, Kamada Y, Noguchi S, Sasaki A \& Hiramatsu Y 2005 Impaired uterine perfusion associated with metabolic disorders in women with polycystic ovary syndrome. Acta Obstetricia and Gynecologica Scandinavica 84 189-195. (https://doi.org/10.1111/ j.0001-6349.2005.00678.x)

Chen JH, Lee MS, Wang CP, Hsu CC \& Lin HH 2017 Autophagic effects of Hibiscus sabdariffa leaf polyphenols and epicatechin gallate (ECG) against oxidized LDL-induced injury of human endothelial cells. European Journal of Nutrition 56 1963-1981. (https://doi.org/10.1007/ s00394-016-1239-4)

Dale PO, Tanbo T, Haug E \& Abyholm T 1998 The impact of insulin resistance on the outcome of ovulation induction with low-dose follicle stimulating hormone in women with polycystic ovary syndrome. Human Reproduction 13 567-570. (https://doi.org/10.1093/ humrep/13.3.567)

Ehrlicher SE, Stierwalt HD, Newsom SA \& Robinson MM 2018 Skeletal muscle autophagy remains responsive to hyperinsulinemia and hyperglycemia at higher plasma insulin concentrations in insulin-resistant mice. Physiological Reports 6 e13810. (https://doi. org/10.14814/phy2.13810)
Eyal O, Jomain JB, Kessler C, Goffin V \& Handwerger S 2007 Autocrine prolactin inhibits human uterine decidualization: a novel role for prolactin. Biology of Reproduction 76 777-783. (https://doi. org/10.1095/biolreprod.106.053058)

Fallah A, Sadeghinia A, Kahroba H, Samadi A, Heidari HR, Bradaran B, Zeinali S \& Molavi O 2019 Therapeutic targeting of angiogenesis molecular pathways in angiogenesis-dependent diseases. Biomedicine and Pharmacotherapy 110 775-785. (https://doi.org/10.1016/j. biopha.2018.12.022)

Ferrara N \& Kerbel RS 2005 Angiogenesis as a therapeutic target. Nature 438 967-974. (https://doi.org/10.1038/nature04483)

Fritzen AM, Frosig C, Jeppesen J, Jensen TE, Lundsgaard AM, Serup AK, Schjerling P, Proud CG, Richter EA \& Kiens B 2016 Role of AMPK in regulation of LC3 lipidation as a marker of autophagy in skeletal muscle. Cellular Signalling 28 663-674. (https://doi.org/10.1016/j. cellsig.2016.03.005)

Frolova AI \& Moley KH 2011a Glucose transporters in the uterus: an analysis of tissue distribution and proposed physiological roles. Reproduction 142 211-220. (https://doi.org/10.1530/REP-11-0114)

Frolova AI \& Moley KH $2011 b$ Quantitative analysis of glucose transporter mRNAs in endometrial stromal cells reveals critical role of GLUT1 in uterine receptivity. Endocrinology 152 2123-2128. (https:// doi.org/10.1210/en.2010-1266)

Halder JB, Zhao X, Soker S, Paria BC, Klagsbrun M, Das SK \& Dey SK 2000 Differential expression of VEGF isoforms and VEGF(164)specific receptor neuropilin-1 in the mouse uterus suggests a role for VEGF(164) in vascular permeability and angiogenesis during implantation. Genesis 26 213-224. (https://doi.org/10.1002/ (SICI)1526-968X(200003)26:3<213::AID-GENE7>3.0.CO;2-M)

Hicklin DJ \& Ellis LM 2005 Role of the vascular endothelial growth factor pathway in tumor growth and angiogenesis. Journal of Clinical Oncology 23 1011-1027. (https://doi.org/10.1200/JCO.2005.06.081)

Iatrakis G, Tsionis C, Adonakis G, Stoikidou M, AnthouliAnagnostopoulou F, Parava M, Vouxinou A, Georgopoulos NA \& Kourounis G 2006 Polycystic ovarian syndrome, insulin resistance and thickness of the endometrium. European Journal of Obstetrics, Gynecology, and Reproductive Biology 127 218-221. (https://doi. org/10.1016/j.ejogrb.2006.01.023)

Kim M, Park HJ, Seol JW, Jang JY, Cho YS, Kim KR, Choi Y, Lydon JP, Demayo FJ, Shibuya M, et al. 2013 VEGF-A regulated by progesterone governs uterine angiogenesis and vascular remodelling during pregnancy. EMBO Molecular Medicine 5 1415-1430. (https://doi. org/10.1002/emmm.201302618)

Krishnapati LS \& Ghaskadbi S 2016 Insulin induces the expression of FGF2 but does not synergize with it during angiogenesis. Microvascular Research 103 55-63. (https://doi.org/10.1016/j.mvr.2015.11.002)

Kumar TR, Wang Y, Lu N \& Matzuk MM 1997 Follicle stimulating hormone is required for ovarian follicle maturation but not male fertility. Nature Genetics 15 201-204. (https://doi.org/10.1038/ng0297201)

Laskowski D, Andersson G, Humblot P, Sirard MA, Sjunnesson Y, Ferreira CR, Pirro V \& Bage R 2018 Lipid profile of bovine blastocysts exposed to insulin during in vitro oocyte maturation. Reproduction, Fertility, and Development 30 1253-1266. (https://doi.org/10.1071/ RD17248)

Li Q, Kannan A, Wang W, Demayo FJ, Taylor RN, Bagchi MK \& Bagchi IC 2007 Bone morphogenetic protein 2 functions via a conserved signaling pathway involving Wnt4 to regulate uterine decidualization in the mouse and the human. Journal of Biological Chemistry 282 31725-31732. (https://doi.org/10.1074/jbc.M704723200)

Li R, Wu J, He J, Wang Y, Liu X, Chen X, Tong C, Ding Y, Su Y, Chen W, et al. 2017 Mice endometrium receptivity in early pregnancy is impaired by maternal hyperinsulinemia. Molecular Medicine Reports $\mathbf{1 5}$ 2503-2510. (https://doi.org/10.3892/mmr.2017.6322)

Li S, Li Q, Yu W \& Xiao Q 2015a High glucose and/or high insulin affects HIF-1 signaling by regulating AIP1 in human umbilical vein https://joe.bioscientifica.com https://doi.org/10.1530/JOE-19-0127 (c) 2019 Society for Endocrinology Published by Bioscientifica Ltd.
Printed in Great Britain 
endothelial cells. Diabetes Research and Clinical Practice 109 48-56. (https://doi.org/10.1016/i.diabres.2015.05.005)

Li Y, Gao R, Liu X, Chen X, Liao X, Geng Y, Ding Y, Wang Y \& He J 2015b Folate deficiency could restrain decidual angiogenesis in pregnant mice. Nutrients 7 6425-6445. (https://doi.org/10.3390/nu7085284)

Lu WH, Shi YX, Ma ZL, Wang G, Liu L, Chuai M, Song X, Münsterberg A, Cao L \& Yang X 2016 Proper autophagy is indispensable for angiogenesis during chick embryo development. Cell Cycle $\mathbf{1 5}$ 1742-1754. (https://doi.org/10.1080/15384101.2016.1184803)

Madrigal-Matute J \& Cuervo AM 2016 Regulation of liver metabolism by autophagy. Gastroenterology 150 328-339. (https://doi.org/10.1053/j. gastro.2015.09.042)

Maisonpierre PC, Suri C, Jones PF, Bartunkova S, Wiegand SJ, Radziejewski C, Compton D, Mcclain J, Aldrich TH, Papadopoulos N, et al. 1997 Angiopoietin-2, a natural antagonist for Tie2 that disrupts in vivo angiogenesis. Science 277 55-60. (https://doi.org/10.1126/ science.277.5322.55)

Marin-Juez R, Jong-Raadsen S, Yang S \& Spaink HP 2014 Hyperinsulinemia induces insulin resistance and immune suppression via Ptpn6/Shp1 in zebrafish. Journal of Endocrinology 222 229-241. (https://doi.org/10.1530/JOE-14-0178)

Mioni R, Mozzanega B, Granzotto M, Pierobon A, Zuliani L, Maffei P, Blandamura S, Grassi S, Sicolo N \& Vettor R 2012 Insulin receptor and glucose transporters mRNA expression throughout the menstrual cycle in human endometrium: a physiological and cyclical condition of tissue insulin resistance. Gynecological Endocrinology 28 1014-1018. (https://doi.org/10.3109/09513590.2012.705367)

Muniyappa R \& Quon MJ 2007 Insulin action and insulin resistance in vascular endothelium. Current Opinion in Clinical Nutrition and Metabolic Care 10 523-530. (https://doi.org/10.1097/ MCO.0b013e32819f8ecd)

Nacar E, Bozkurt YA, Koc A \& Nacar A 2016 Immunohistochemical investigation of endometrial leukocytes in implantation period in rats with streptozotosin-induced diabetes. Polish Journal of Pathology $\mathbf{6 7}$ 54-59. (https://doi.org/10.5114/pjp.2016.59191)

Niswender GD, Juengel JL, Silva PJ, Rollyson MK \& Mcintush EW 2000 Mechanisms controlling the function and life span of the corpus luteum. Physiological Reviews 80 1-29. (https://doi.org/10.1152/ physrev.2000.80.1.1)

Okada H, Tsuzuki T, Shindoh H, Nishigaki A, Yasuda K \& Kanzaki H 2014 Regulation of decidualization and angiogenesis in the human endometrium: mini review. Journal of Obstetrics and Gynaecology Research 40 1180-1187. (https://doi.org/10.1111/jog.12392)

Reynolds LP, Killilea SD \& Redmer DA 1992 Angiogenesis in the female reproductive system. FASEB Journal 6 886-892. (https://doi. org/10.1096/fasebj.6.3.1371260)

Ribeiro M, Lopez De Figueroa P, Blanco FJ, Mendes AF \& Carames B 2016 Insulin decreases autophagy and leads to cartilage degradation. Osteoarthritis and Cartilage 24 731-739. (https://doi.org/10.1016/j. joca.2015.10.017)

Scharpfenecker M, Fiedler U, Reiss Y \& Augustin HG 2005 The Tie-2 ligand angiopoietin-2 destabilizes quiescent endothelium through an internal autocrine loop mechanism. Journal of Cell Science $\mathbf{1 1 8}$ 771-780. (https://doi.org/10.1242/jcs.01653)

Schulte MM, Tsai JH \& Moley KH 2015 Obesity and PCOS: the effect of metabolic derangements on endometrial receptivity at the time of implantation. Reproductive Sciences 22 6-14. (https://doi. org/10.1177/1933719114561552)

Senft D \& Ronai ZA 2015 UPR, autophagy, and mitochondria crosstalk underlies the ER stress response. Trends in Biochemical Sciences $\mathbf{4 0}$ 141-148. (https://doi.org/10.1016/j.tibs.2015.01.002)

Su Y, Wu J, He J, Liu X, Chen X, Ding Y, Zhang C, Chen W, Wang Y \& Gao R 2017 High insulin impaired ovarian function in early pregnant mice and the role of autophagy in this process. Endocrine Journal $\mathbf{6 4}$ 613-621. (https://doi.org/10.1507/endocrj.EJ16-0494)

Von Wolff M, Ursel S, Hahn U, Steldinger R \& Strowitzki T 2003 Glucose transporter proteins (GLUT) in human endometrium: expression, regulation, and function throughout the menstrual cycle and in early pregnancy. Journal of Clinical Endocrinology and Metabolism $\mathbf{8 8}$ 3885-3892. (https://doi.org/10.1210/jc.2002-021890)

Wang TS, Gao F, Qi QR, Qin FN, Zuo RJ, Li ZL, Liu JL \& Yang ZM 2015 Dysregulated LIF-STAT3 pathway is responsible for impaired embryo implantation in a streptozotocin-induced diabetic mouse model. Biology Open 4 893-902. (https://doi.org/10.1242/ bio.011890)

Winterhager E, Gellhaus A, Blois SM, Hill LA, Barr KJ \& Kidder GM 2013 Decidual angiogenesis and placental orientation are altered in mice heterozygous for a dominant loss-of-function Gja1 (connexin43) mutation. Biology of Reproduction 89 111. (https://doi.org/10.1095/ biolreprod.113.111690)

Yang O, Li J, Chen H, Li J \& Kong J 2016 Atorvastatin ameliorates endothelium-specific insulin resistance induced by high glucose combined with high insulin. Molecular Medicine Reports 142791 2798. (https://doi.org/10.3892/mmr.2016.5564)

Zakaria R, Ismail Z \& Chatterjee A 2000 Cyproterone acetate and reversal of the impaired endometrial decidualization in streptozotocindiabetic pseudopregnant rats. Pharmacological Research 42 183-186. (https://doi.org/10.1006/phrs.2000.0673)

Zeng Y, Zhang L \& Hu Z 2016 Cerebral insulin, insulin signaling pathway, and brain angiogenesis. Neurological Sciences 37 9-16. (https://doi. org/10.1007/s10072-015-2386-8)

Zhang C, Wu J, He J, Liu X, Chen X, Tong C, Ding Y, Geng Y, Chen W, Wang Y, et al. 2017 The regulation of high insulin levels on ovary apoptosis in early pregnant mice. Biochemical and Biophysical Research Communications 483 786-792. (https://doi.org/10.1016/j. bbrc.2016.12.041)

Zhao J, Zhai B, Gygi SP \& Goldberg AL 2015 mTOR inhibition activates overall protein degradation by the ubiquitin proteasome system as well as by autophagy. PNAS 112 15790-15797. (https://doi. org/10.1073/pnas.1521919112)

Zunker P, Schick A, Buschmann HC, Georgiadis D, Nabavi DG, Edelmann M \& Ringelstein EB 1996 Hyperinsulinism and cerebral microangiopathy. Stroke 27 219-223. (https://doi.org/10.1161/01. str.27.2.219)

Received in final form 8 August 2019

Accepted 14 August 2019

Accepted Preprint published online 14 August 2019 https://joe.bioscientifica.com https://doi.org/10.1530/JOE-19-0127 (c) 2019 Society for Endocrinology Published by Bioscientifica Ltd. Printed in Great Britain 